\title{
Desenvolvimento humano e bem-estar no meio rural como superação da vulnerabilidade: 0 caso de Arroio do Tigre/RS 1
}

\begin{abstract}
Resumo
Este trabalho tem como tema o desenvolvimento humano e a diversificação dos meios de vida, conceitos esses entendidos como sinônimo de melhoria de vida e superação das vulnerabilidades, dando destaque para a necessidade de estudos sobre bem-estar no meio rural. A importância deste estudo está em analisar a cultura do tabaco como processo que torna os indivíduos dependentes e de uma cadeia produtiva que, mesmo trazendo ganhos produtivos e econômicos, não reflete esses ganhos em bem-estar e desenvolvimento humano e rural. Teoricamente, buscou-se compreender a abordagem das capacitações, de Amartya Sen, e a dos livelihoods, de Frank Ellis, como perspectivas que permitem entender o desenvolvimento para além do aspecto financeiro, levando em consideração o bem-estar no meio rural. Metodologicamente, foram elaborados dois índices que retrataram os meios de vida (IMV) e as condições de vida (ICV), permitindo, assim, um primeiro diagnóstico sobre cinco dimensões, a saber: econômica, social, humana, ambiental e física. A pesquisa deu-se no município de Arroio do Tigre (RS), em duas etapas: a primeira, por um estudo tipo survey, com 38 famílias, e a segunda com entrevistas semiestruturadas, com 15 famílias, a fim de entender melhor o que torna (ou não) estas famílias fumicultoras dependentes e vulneráveis. Os primeiros resultados demonstraram que aqueles produtores mais dependentes da cadeia produtiva do tabaco eram mais vulneráveis e, portanto, tinham um índice de meios e condições de vida pior que produtores diversificados. Ainda, estes resultados permitiram identificar quais dimensões são mais ou menos afetadas pela dependência da cadeia do tabaco.
\end{abstract}

Palavras-chave: Desenvolvimento Humano. Bem-estar. Vulnerabilidade social. Meios de Vida. Fumicultura.

\footnotetext{
${ }^{1}$ Versões anteriores deste trabalho foram apresentadas no VI Seminário Internacional de Desenvolvimento Regional da Universidade de Santa Cruz do Sul (UNISC), em 2013, e no Congresso Internacional da Associação Latino Americana de Sociologia Rural (ALASRU), em 2014.

${ }^{2}$ Mestre em Ciências Sociais. Doutoranda em Sociologia. tanise1208@yahoo.com.br

${ }^{3}$ Doutora em Desenvolvimento Rural. Professora da Universidade Federal da Fronteira Sul (UFFS). ane_rambo@yahoo.com.br

${ }^{4}$ Doutor em Sociologia, Professor do PPGS e PGDR da Universidade Federal do Rio Grande do Sul (UFRGS).schneider@ufrgs.br
} 


\begin{abstract}
This work has as its theme the human development and diversification of livelihoods, these concepts understood as synonym for improvement of life and overcoming vulnerabilities, highlighting the need for studies on welfare in rural areas. The importance of this study is to analyze the culture of tobacco as a process that makes them dependent individuals and a productive chain that even bringing productive and economic gains, does not reflect these gains in well-being and human and rural development. Theoretically, we attempted to understand the capability approach of Amartya Sen and the livelihoods of Frank Ellis as perspectives that permit to understand the development beyond the financial aspect, taking into account the well-being in rural areas. Methodologically, two indices were elaborated that portrayed livelihoods (IMV) and living conditions (ICV), thus allowing a first diagnosis on five dimensions, namely: economic, social, human, physical and environmental. The research took place in the municipality of Arroio do Tigre (RS) in two phases: first by a survey type study with 38 families and the second with semi-structured interviews with 15 families, in order to better understand what makes it (or not) these tobacco growing families dependent and vulnerable. Early results have shown that these producers more dependent on tobacco production chain were more vulnerable and therefore they had an index of livelihoods and living conditions worse than diversified producers. Moreover, these results permitted to identify dimensions which are more or less affected by the tobacco dependency chain.
\end{abstract}

Keywords: Human Development. Welfare. Social vulnerability. Livelihoods. Tobacco farming.

\title{
1 Introdução
}

O presente artigo insere-se nas discussões sobre desenvolvimento e diversificação no meio rural, temáticas que configuram as agendas políticas e científicas dos últimos anos, dando destaque para a necessidade de estudos sobre bem-estar no meio rural como sinônimo de desenvolvimento e superação das vulnerabilidades. A importância deste estudo está em analisar a cultura do tabaco como processo agrícola que torna os indivíduos dependentes de uma cadeia produtiva e, portanto, mais vulneráveis. Este é o paradoxo que mobiliza inicialmente esta pesquisa. Como entender a relação entre ter boas condições econômicas e péssimas condições de vida? De forma mais geral, na tentativa de responder a esse paradoxo, percebem-se diversas formas de analisar desenvolvimento humano.

Dentre o que se propõe explicar inicialmente, é preciso considerar que o conceito de desenvolvimento caracteriza-se por um processo que significa, ao mesmo tempo, diversificar os "meios de vida" (ELLIS, 2000) a fim de alcançar a redução das vulnerabilidades e, consequentemente, melhoria nas condições de vida. Logo, a ampliação das capacitações dos indivíduos (no caso, das famílias rurais) pode ser realizada pela diversificação das formas de organização econômica e produtiva. Um leque maior de oportunidades e opções de escolha é fundamental para que esses indivíduos possam estabelecer estratégias de combate às mais distintas formas de vulnerabilidades a que estão submetidos, bem como incrementar a sua resiliência.

Nesta abordagem, o objetivo central é compreender as complexas dimensões da 
vida humana e como elas se configuram e transformam a vida dos indivíduos. Portanto, utiliza-se o enfoque das capacitações de Amartya Sen, focando nos indivíduos e em como estes conseguem criar estratégias de sobrevivência a partir de seus recursos/intitulamentos/ativos. Tal perspectiva teórica é operacionalizada pela abordagem da diversificação dos meios de vida de Frank Ellis, através de cinco capitais/dimensões (ambiental, física, financeira, humana e social), que representam os meios de vida dos fumicultores.

Estes referenciais teóricos podem ser facilmente encontrados na realidade cotidiana, como é o caso da região fumicultora do Rio Grande do Sul e mais especificamente o município de Arroio do Tigre: a partir de uma pujante economia assentada na produção de tabaco, percebe-se, sem dificuldades, o descompasso entre crescimento econômico e tecnológico de um lado, e vulnerabilidade social e precariedade das condições de vida de outro. Nesse sentido, deseja-se analisar se fumicultores com maior diversificação dos seus meios de vida (ativos ou recursos) apresentam, consequentemente, meIhores condições de vida. A ênfase deste estudo-piloto está em captar em que medida as mudanças no meio rural, e sua consequente especialização produtiva, traduziram-se em melhoria de bem-estar para estas populações. Destarte, a escolha das abordagens de Sen e Ellis, para compreender desenvolvimento como melhoria das condições de vida, justifica-se pelo entendimento de que o atual modelo de agricultura de exportação, pautado basicamente no fomento de commodities, parece ser cada vez mais incapaz de apresentar alternativas à crescente vulnerabilidade social e econômica do campo, principalmente quando se trata de agricultura familiar.

Segundo Niederle e Grisa (2008), diversos estudos sobre o meio rural têm demonstrado a revalorização da diversidade a partir de novas oportunidades aos atores locais, criando dinâmicas de desenvolvimento mais autônomas, que interliguem o local ao global. Contudo, ainda existem poucos trabalhos, principalmente no Brasil, que analisam correlações entre bem-estar e diversificação, principalmente com produtores integrados às diferentes cadeias produtivas. Nesse sentido, pode-se dizer que a contribuição prática-política deste trabalho advém do fato de que a superação do modelo agrícola vigente, da integração completa à cadeia produtiva, impõe-nos pensar formas mais sustentáveis e que tragam melhorias às condições de vida, não somente aos produtores de tabaco, mas à agricultura familiar em geral, uma vez que estas abordagens apontam elementos essenciais para pensar em que condições produzem e vivem os pequenos agricultores.

Desta forma, o presente artigo apresenta, a partir dos referenciais teórico-metodológicos, uma análise da diversificação dos meios de vida, tendo como informantes produtores de tabaco do município de Arroio do Tigre - Rio Grande do Sul, o qual se destaca nessa produção, mas, ao mesmo tempo, parece não ter esta produtividade agrícola traduzida em melhores condições de vida para a população. Empiricamente, foram realizadas 38 entrevistas do tipo survey, e 11 entrevistas semiestruturadas, para apreender a realidade da agricultura familiar do município, bem como uma entrevista com a professora de uma escola local, que também já havia sido produtora de fumo (informante). Como resultado inicial, percebeu-se que famílias menos dependentes da cultura do tabaco apresentaram melhores condições de vida, ou seja, eram menos vulneráveis às variações do sistema integrado fumageiro. Ainda, foi possível apreender as estratégias adotadas pelas famílias, para superar a vulnerabilidade, a partir da diversificação no meio rural. 


\section{Superando a vulnerabilidade e melhorando a qualidade de vida (QV) através das capacitações}

Ainda é comum tratar desenvolvimento como sinônimo de crescimento econômico. Com o objetivo de simplificar as formas de medir desenvolvimento, levava-se em consideração quase que essencialmente a evolução de indicadores tradicionais de economia, como o Produto Interno Bruto (PIB) per capita. Conforme Veiga (2006), até o início dos anos de 1960, não se tinha a necessidade de diferenciar desenvolvimento de crescimento econômico, pois poucas nações desenvolvidas eram as que haviam enriquecido com o advento da industrialização. A ideia de desenvolvimento tratava-se essencialmente das relações econômicas, com ênfase nas especialidades técnica e produtiva, eficiência e eficácia da produção material e racionalização da organização social.

Especificamente no mundo rural, a até então vigente máxima da especialização começa a perder espaço nos debates sobre desenvolvimento, evidenciando aspectos como diversidade e diversificação, principalmente nos anos 90. Como já foi apontado em outro trabalho (SCHNEIDER, 2010b), estudos recentes expressam que o futuro do mundo rural será determinado pelo modo como os agrupamentos humanos serão capazes de gerir a diversidade das espécies (biodiversidade), dos solos e dos ecossistemas em que vivem. Ou seja, é preciso redirecionar o foco das pesquisas para o reconhecimento de que é necessário entender a diversidade dos meios e o modo como os indivíduos lidam com as adversidades e os condicionantes nos contextos em que vivem. Dessa forma, a abordagem do desenvolvimento vai além da simples posse de bens materiais, de capitais, tais como os recursos financeiros, uma vez que esdes não são sinônimos de garantia de acessos, de diminuição de vulnerabilidades, de riscos e incertezas. A questão que se coloca é compreender em que medida os meios que as pessoas detêm lhes permitem fazer escolhas e agir de modo a melhorarem sua qualidade de vida e bem-estar em suas várias dimensões ${ }^{5}$. 0 desenvolvimento representa a condição que se alcança quando se exerce a liberdade de escolha quanto aos meios de vida - os fins almejados, os quais os meios permitem alcançar.

Assim, tem-se, na abordagem das capacitações de Amartya Sen, a possibilidade "teórica" de analisar o desenvolvimento sob o viés dos indivíduos e suas capacitações (ou a falta destas) para lidar com as adversidades do cotidiano. A proposta de Sen objetiva tirar o foco das ações sobre os fins ou resultados, materializados em variáveis como renda, posse de bens ou capitais, e privilegiar o fortalecimento dos meios e modos que os indivíduos dispõem para lidar com as adversidades dos contextos em que vivem, com os riscos sociais, com as incertezas.

Pode-se dizer que, operacionalmente, Sen (2001) distingue meios e fins com base nos conceitos de entitlements (intitulamentos) e functionings (funcionamentos). Os intitulamentos representam o conjunto de combinações de bens ou mercadorias que cada

\footnotetext{
${ }_{5}^{5}$ Para melhor referenciar o conceito "qualidade de vida", ver os textos de ALLARDT, Erik. Tener, Amar, Ser: una alternativa al modelo sueco de investigación sobre el bienestar; ERIKSON, Robert. Descripciones de La desigualdad: el enfoque sueco de La investigación sobre el bienestar, in Sen e Nussbaum, Quality of Life (1996). No contexto brasileiro, tem-se como referencial os trabalhos de Selene Herculano.
} 
pessoa pode ou está apta a possuir, ou, ainda, os meios para atingir determinados fins, as condições para a realização de escolhas, sendo estabelecidos por ordenamentos legais, políticos e econômicos (KAGEYAMA, 2008; WAQUIL et al., 2007). Os funcionamentos, por sua vez, remetem às realizações dos indivíduos, às reais oportunidades de escolha acerca de possíveis estilos de vida. Ou seja, o indivíduo necessita ter a capacidade de realizar um funcionamento (capability to function), refletindo a liberdade da pessoa para levar determinado tipo de vida ou outro (SEN, 2001; KAGEYAMA, 2008). Nesta perspectiva, o desenvolvimento só pode ser alcançado quando os indivíduos dispõem dos "meios" pelos quais podem realizar os "fins" que almejam, podendo ultrapassar obstáculos pré-existentes, que condicionam, ou ainda que restrinjam a liberdade de escolha.

Assim, avaliar, medir ou mensurar condições de vida torna-se uma tarefa complexa, uma tentativa de compreender como realmente vivem as pessoas, principalmente aquelas que se encontram em situações de vulnerabilidade (sejam elas financeiras, humanas, físicas, ambientais ou sociais). Entender o desenvolvimento requer mais que uma análise das condições de renda dos indivíduos. Requer uma abordagem integral, que observe os funcionamentos e as capacitações dos indivíduos e como estes conseguem melhorar suas condições de vida. Estar vulnerável representa muito mais que "estar abaixo da linha da pobreza". Portanto, o estudo dos meios e condições de vida, que permitem que um indivíduo ou pessoa tenha a capacidade de optar por aquilo que deseja e que lhe traz maior grau de satisfação, é o que resume e define uma análise do desenvolvimento na perspectiva humana.

\section{Desenvolvimento como superação das vulnerabilidades e a questão rural: a diversificação dos meios de vida}

Com base nestes debates em relação à abordagem teórico-metodológica da proposta de Amartya Sen, muitos estudiosos do desenvolvimento rural passaram a rediscutir as estratégias de combate à pobreza, buscando esclarecer que "mais importante do que dar aos pobres comida seria dotá-los de recursos que estimulassem suas capacidades, fortalecendo os meios de que dispõem para realizar suas atividades" (SHNEIDER; FREITAS, 2013, p. 123).

Diante disso, a possibilidade de implementar a abordagem das capacitações pode ser visualizada por meio da sua relação com a perspectiva dos livelihoods (meios de vida) de Frank Ellis, a qual, segundo Perondi et al. (2009), foi inicialmente utilizada como uma ferramenta analítica, para compreender a pobreza rural no mundo, tentando explicar como as pessoas faziam para sobreviver em situações de risco, incerteza, vulnerabilidade social e econômica (BEBBINGTON, 1999; ELLIS, 2000; SCOONES, 2009). A análise dos livelihoods implica na busca de fortalecimento da base de recursos disponíveis aos agricultores e da capacidade de luta constante por autonomia e liberdade frente a um contexto de hostilidade, privação e adversidade (PLOEG, 2008). Assim, para alcançar meIhores condições de vida, é preciso compreender a capacidade que determinado indiví-

duo/grupo apresenta e como consegue lidar com o sistema de oportunidades oferecido pela sociedade, pelo Estado ou pelo mercado.

Neste ponto, é possível perceber a correlação existente entre a abordagem dos 
meios de vida e a das capacitações de Amarty Sen: a interface está na ideia de que a ampliação das capacitações, no caso das famílias rurais produtoras de tabaco, pode ser realizada pela diversificação das formas de organização econômica e produtiva, social e ambiental. Logo, pode-se dizer que, quanto mais diversificada for a unidade produtiva, maiores serão as possibilidades de escolha e maiores as estratégias que poderão ser estabelecidas para o combate da vulnerabilidade (SCHNEIDER, 2010a).

Para Ellis (2000), a diversificação dos meios de vida refere-se ao processo pelo qual as famílias rurais estabelecem um portfólio de atividades e capacidades de apoio social para sobreviver e melhorar suas condições de vida. Ademais, o conceito de diversidade manifesta-se pelas diferentes formas de renda, atividades, ocupações, sistemas de produção, condições de trabalho, dependência produtiva e humana, etc. Trata-se, então, da criação de mecanismos/estratégias de diversificação que contribuam de forma decisiva na operacionalização de ações para o desenvolvimento rural, a fim de fortalecer os meios de vida dos indivíduos. Conforme Schneider (2010a), tal estratégia parte da diversificação dos ativos disponíveis, dados pelo conjunto de capitais natural, físico, humano, social, financeiro, os quais podem estar relacionados às atividades agrícolas ou não agrícolas, dentro ou fora da propriedade. O resultado dessas iniciativas ou estagnações geram (ou não) melhoria de qualidade de vida e, consequentemente, desenvolvimento rural, bem como incremento da resiliência.

Trazendo estes debates para o estudo de caso do município de Arroio do Tigre, e com base nos trabalhos de Perondi et al. (2009), pode-se dizer que a diversificação dos meios de vida, no contexto rural, é um fator determinante à agricultura familiar do tabaco. Segundo o autor, mesmo que a especialização pareça propulsora de vantagens em termos financeiros, esta prática necessita de estabilidade econômica, trabalho exaustivo e intensificado, que leva, muitas vezes, ao desgaste humano e a não recompensa financeira. Não obstante, os meios e as capacidades de que dispõem estes produtores acabem compelindo-os e pressionando-os a se manter fortemente dependentes e subordinados à cadeia produtiva de tabaco.

Por esse motivo, a diversificação dos meios de vida parece ser um caminho que apresenta alternativas para maior estabilidade e autonomia às famílias de produtores. Implica na construção de um portfólio que permita exercer o direito de escolha/opção, as quais podem variar em um gradiente, alterando-se entre aqueles que optam por permanecer dependentes e especializados na produção de tabaco, aqueles que apenas reduzem a produção, sem abandonar o cultivo do fumo, e, por fim, aqueles que decidem deixar a produção e se dedicar a outros cultivos. A partir desses gradativos, torna-se possível estabelecer condições de diversificação, as quais dependerão fundamentalmente das opções que vierem a seguir, da disponibilidade de recursos a que tiverem acesso e da capacidade de utilizarem estes recursos. Com a figura que segue, pretende-se evidenciar, por meio de um paralelo, as relações entre as abordagens de Amartya Sen e Frank Ellis. A figura expressa ainda como os referenciais teóricos resultaram em instrumentos de pesquisa (questionários) que deram origem ao Índice dos Meios de Vida e ao Índice das Condições de Vida. 
Figura 1 - A relação entre desenvolvimento e diversificação dos meios de vida

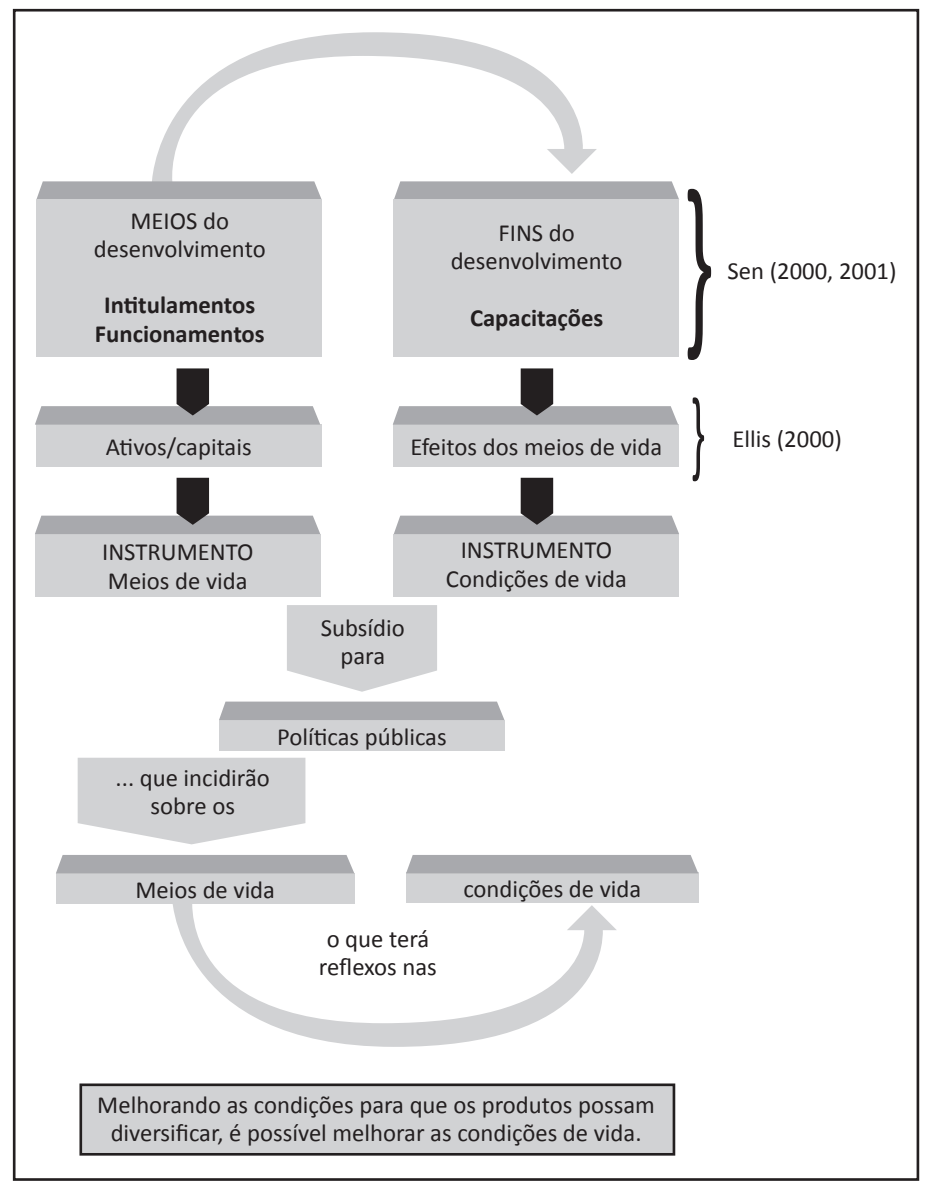

Fonte: Elaborado pelos autores.

A partir da síntese apresentada na Figura 1, as análises dos resultados dos índices a serem levantados, além de apontarem em que medida os níveis de diversificação interferem nas condições de vida, poderão ressaltar quais dimensões (natural, físico, humano, social, financeiro) mostram-se mais vulneráveis. Ademais, o fato de os resultados dos índices serem obtidos com os próprios agricultores produtores de tabaco representa uma fortaleza desta proposta teórico-metodológica, uma vez que isso significa maior possibilidade de adequação das políticas às necessidades dos agricultores familiares, o que pode ser confirmado na fase de entrevistas semiestruturadas. ${ }^{6}$

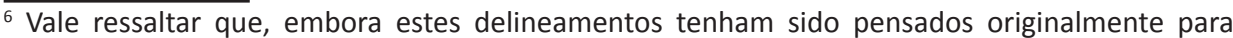
produtores de tabaco, pode-se dizer que o modelo aqui proposto também se aplicaria a outras realidades rurais, como, por exemplo, em regiões vulneráveis e de baixos índices de desenvolvimento, mas com PIB elevado, ou altos valores de produção em relação aos chamados cash crops (cultivos/produtos comerciais), como é o caso da soja e da cana-de-açúcar.
} 


\section{Referenciais metodológicos para analisar a diversificação dos meios de vida}

Com base nos referenciais já apresentados, a metodologia proposta consistiu na elaboração de dois instrumentos, que propõem considerar tanto os meios quanto os fins do desenvolvimento, conforme expõe Amartya Sen. Para tanto, é importante relacionar qual a percepção dessas famílias acerca disto, para dar conta da ideia de Sen (2001), ao afirmar que o padrão, a qualidade ou as condições de vida não se medem pela posse de um conjunto de bens, nem pela qualidade a eles inerente, mas pela capacidade das famílias em utilizar esses bens para obter satisfação ou felicidade. Nesse sentido, se, por um lado, não é suficiente ter conhecimento dos bens ou ativos que as famílias dispõem, por outro, também não é suficiente apenas ter conhecimento da percepção dessas famílias sobre suas condições de vida. Esta é a proposição que justifica a elaboração de dois instrumentos de pesquisa, bem como uma posterior entrevista semiestruturada.

\subsection{Quanto à unidade de análise}

Neste estudo, a família ou household ${ }^{7}$ foi considerada a unidade de análise, uma vez que está coesa com os estudos sobre estratégias de reprodução dos agricultores familiares. Tal unidade permite identificar as relações entre os indivíduos, as relações "face a face", na estrutura familiar, bem como as relações da unidade com o coletivo e a comunidade em geral. Segundo Ellis (2000), análises sobre o meio familiar tornam-se importantes na identificação de normas, valores e regras que influenciam as ações dos indivíduos e mesmo a conduta destes na formulação de suas estratégias, tanto individuais como familiares, em busca da melhoria nas condições de vida. Para o autor, é na família que ocorrem intensas relações sociais e econômicas interdependentes; é onde se pode compreender relações de confiança, de conflito, de reciprocidade, de etnicidade e comunitárias, as quais não podem ser compreendias por meio de casos individuais.

\subsection{Quanto aos instrumentos de pesquisa}

Os instrumentos de pesquisa dizem respeito, primeiro, a dois questionários, que apontam para o que se denominou como meios e fins do desenvolvimento; portanto, são complementares. Ambos são do tipo fechado e de múltipla escolha, que variaram de valores negativos ou baixos a valores positivos ou altos, acerca dos capitais e dos efeitos destes ativos sobre as condições de vida. Cada questionário está organizado em cinco dimensões - natural, humano, social, financeiro e físico (tal como será detalhado na seção 4.3).

O primeiro questionário buscou captar os aspectos objetivos, ou seja, os condicionantes/intitulamentos (SEN, 2001) ou ativos (assets), tal como trata Ellis (2000). Os

\footnotetext{
${ }^{7}$ O termo household difere-se de "família" em si, pois não se trata diretamente de relações consanguíneas, mas de relações sociais, podendo os membros do household serem de fora da família, mas que estão permanentemente na residência. Para Ellis (2000), o termo busca definir o lugar onde o grupo social reside e compartilha as mesmas refeições e toma as decisões sobre os "rumos da família", de forma conjunta, sejam elas decisões sobre a utilização dos recursos ou sobre a organização da propriedade.
} 
intitulamentos/ativos caracterizarão os meios de vida e dizem respeito ao conjunto de atividades, formas de acesso ou uso que determinam o modo de viver de um indivíduo ou família, sendo denominados "capitais". Já o segundo questionário, propôs levantar os aspectos subjetivos ou efeitos do desenvolvimento, referentes a cada meio de vida identificado pelo primeiro questionário.

Cabe explicar ainda que, nos referidos instrumentos do survey, para cada pergunta acerca dos capitais - questionário sobre meios de vida - há uma pergunta correspondente aos efeitos - questionário sobre condições de vida - de modo que possibilite o estabelecimento de relações entre meios e fins. Tais instrumentos deram origem a índices gerais - dos meios de vida (IMV) e das condições de vida (ICV) - e a índices por dimensões (capitais ou efeitos). Ambos são do tipo fechado e de múltipla escolha; variaram de zero a um, acerca dos capitais e dos efeitos destes capitais sobre as condições de vida, observando que, quanto mais próximo de 1, melhor o índice.

O IMV resultou da média simples dos capitais, enquanto o ICV resultou da média simples dos efeitos. Ressalta-se que capitais e efeitos têm o mesmo peso na composição da média geral de seus índices, sendo que o índice correspondente a cada capital ou efeito também resultou da média simples das respostas obtidas, tendo todas as perguntas o mesmo peso.

Em relação às entrevistas semiestruturadas, estas seguiram um roteiro elaborado a partir da primeira pesquisa no município (38 entrevistados), em função de algumas dúvidas que apareceram nos primeiros instrumentos a partir dos resultados iniciais.

A estruturação da entrevista ocorreu da seguinte forma:

\section{Quadro 1 - Roteiro orientador das entrevistas (segunda etapa da pesquisa)}

\begin{tabular}{|l|l|}
\hline 1. Composição familiar & $\begin{array}{l}\text { 7. Acha que trabalhar com fumo } \\
\text { prejudica a saúde? }\end{array}$ \\
\hline $\begin{array}{l}\text { 2. Atividades desenvolvidas na } \\
\text { propriedade }\end{array}$ & $\begin{array}{l}\text { 8. Quais os motivos que o fariam deixar } \\
\text { de plantar fumo? }\end{array}$ \\
\hline 3. Atividades que geram renda & $\begin{array}{l}\text { 9. Sente falta de políticas do Estado? } \\
\text { Quais? }\end{array}$ \\
\hline 4. Como ocorre o trabalho com fumo? & $\begin{array}{l}\text { 10. Gostaria que os filhos continuassem } \\
\text { plantando? }\end{array}$ \\
\hline $\begin{array}{l}\text { 5. Como considera o trabalho no fumo } \\
\text { e na agricultura em geral? }\end{array}$ & $\begin{array}{l}\text { 11. O que acredita ser uma vida boa para } \\
\text { todos da família? }\end{array}$ \\
\hline 6. Quem são os envolvidos com o cultivo? & 12. Contato futuro. \\
\hline
\end{tabular}

Fonte: Elaborado pelos autores.

Com este roteiro, buscou-se entender como pensam as pessoas que trabalham na fumicultura, como transcorre seu dia a dia, as atividades desenvolvidas na propriedade, como percebem a questão da saúde e as condições de trabalho; a presença dos filhos na plantação de fumo, os problemas do passado e as perspectivas para o futuro. A necessidade de tais informações advém do esforço de encontrar elementos que tentem definir diversificação dos meios de vida para fumicultura, como, por exemplo, aspectos 
relacionados ao meio ambiente, trabalho, receita, produção, mão-de-obra, autoconsumo, etc.

Para tanto, foram realizadas 11 entrevistas com produtoras de fumo e mais uma entrevista com uma professora de uma escola do meio rural, uma importante informante local que também já havia sido produtora de fumo.

\subsection{Quanto aos indicadores}

Os indicadores que compõem os instrumentos survey, bem como a entrevista semiestruturada, foram elaborados a partir da proposta teórico-metodológica já apresentada. Assim, têm-se indicadores multivariados, os quais abarcaram os aspectos natural, físico, humano, financeiro e social e foram subdivididos em capitais (que remetem aos meios de vida) e efeitos (no caso das condições de vida). Para cada capital, apresenta-se uma pergunta correspondente ao efeito no instrumento sobre as condições de vida. 0 Quadro 2 apresenta a composição dos capitais e efeitos que compõem a avaliação dos meios e condições de vida.

\section{Quadro 2 - Capitais, efeitos e seus componentes}

\begin{tabular}{|l|l|}
\hline Capitais/Efeitos & \multicolumn{1}{c|}{ Componentes } \\
\hline Natural & $\begin{array}{l}\text { Água, solos, preservação da flora; uso de lenha; uso de insumos } \\
\text { químicos. }\end{array}$ \\
\hline Humano & Educação, saúde e nutrição; condições do trabalho agrícola. \\
\hline Social & $\begin{array}{l}\text { Relações entre indivíduos, com a comunidade, e atividades culturais; } \\
\text { informações produtivas, assistência técnica. }\end{array}$ \\
\hline Financeiro & $\begin{array}{l}\text { Receitas e atividades produtivas dentro e fora da propriedade } \\
\text { (gastos e custos); financiamentos; mão-de-obra. }\end{array}$ \\
\hline Físico & Moradia e infraestrutura; máquinas para trabalho agrícola; segurança. \\
\hline
\end{tabular}

Fonte: Elaborado pelos autores, com base em Ellis (2000).

Os dados obtidos com a aplicação dos instrumentos foram tabulados e deram origem a gráficos no formato radar (biogramas), nos quais quanto maior a área do gráfico e maior o equilíbrio entre os eixos, melhores os meios e as condições de vida respectivamente. A cada grau de diversificação, haverá pelo menos dois biogramas: um relativo aos meios de vida, e outro, às condições de vida.

\subsection{Categorização do grupo de entrevistados}

Nesta seção, destacam-se os elementos que levaram à classificação dos produtores de tabaco quanto ao seu grau de diversificação. Esta classificação seguiu definições operacionais e heuristicamente viáveis, considerando duas variáveis independentes: (a) o valor relativo da produção de tabaco vis a vis, o total da produção agrícola em um estabelecimento [valor bruto da produção de uma família como variável que determinará o 
montante que o tabaco representa nas receitas/ganhos totais das atividades produtivas (agrícolas ou não agrícolas, dentro ou fora da propriedade)]; (b) a quantidade de tempo de trabalho que a família dedica ao cultivo do tabaco em relação às demais atividades produtivas que exerce.

A partir disto, foi possível classificar os agricultores produtores de tabaco em três categorias, variando de famílias diversificadas (até $50 \%$ da receita e até $50 \%$ do tempo de trabalho dedicado ao tabaco) a especializadas (mais de $75 \%$ da receita ou do tempo de trabalho voltado ao tabaco), passando pelas pouco diversificadas (demais casos que não se enquadram nos anteriores). Essa categorização vai ao encontro das proposições de Ellis (2000), quando aponta que a diversificação se refere ao processo pelo qual as famílias rurais constroem um portfólio de atividades e capacidades para sobreviver e melhorar suas condições de vida.

A partir dessas tipologias, foi possível relacionar graus de diversificação, meios de vida e condições de vida, a saber:

1 - Em termos operacionais e metodológicos, iniciaram-se as análises pela mensuração e classificação dos agricultores segundo o grau de diversificação (receitas e tempo de trabalho).

2 - Em seguida, foram levantadas informações que definiram os fatores que determinam a possibilidade (ou não) de diversificar. Esses fatores remetem aos capitais (natural, humano, social, financeiro, físico), a sua posse (ou não) e ao uso que se faz (ou não) deles, o que caracteriza os meios de vida.

3 - Ao fim, partiu-se para a verificação dos efeitos que esses ativos têm sobre as condições de vida dos diferentes grupos (diversificados, pouco diversificados e especializados). Cada um destes grupos apresentará dois biogramas: um relativo aos meios de vida e outro às condições de vida.

\section{Os meios e as condições de vida produtores de tabaco}

O município de Arroio do Tigre, no Rio Grande do Sul/Brasil, compõe o território rural Centro Serra desde 2007, sendo assistido pelo Programa de Desenvolvimento Sustentável dos Territórios Rurais (Pronat), o qual atende regiões do Brasil que se encontram em situação de vulnerabilidade socioeconômica e objetivam o desenvolvimento regional sustentável e a garantia de direitos sociais e cidadania.

Disso, pode-se inferir que a produção do tabaco mostra impactos pouco significativos sobre os indicadores econômicos nestas regiões, uma vez que não foi suficiente para evitar a criação de territórios rurais ou da cidadania nas respectivas localidades.

A localização do município pode ser observada na Figura 2. 
Figura 2 - Localização do município de Arroio do Tigre/RS

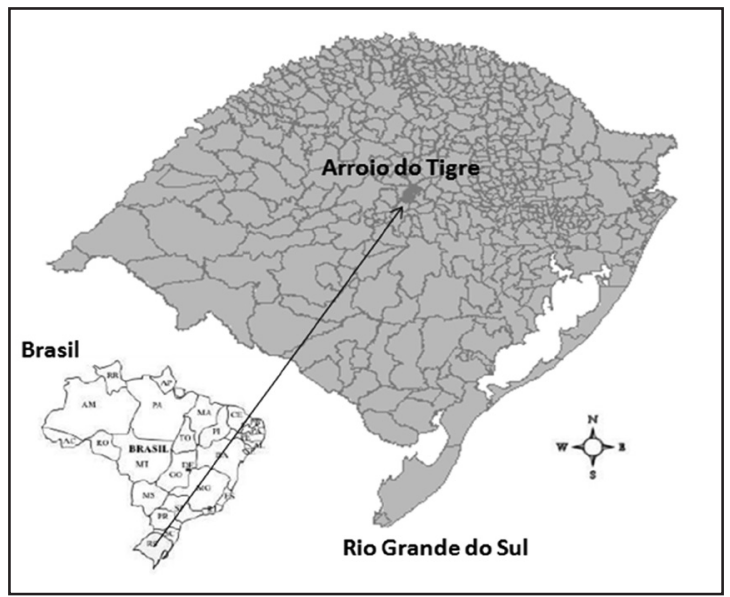

Fonte: Elaborado pelos autores.

\subsection{A pesquisa de campo e os primeiros resultados}

Em janeiro de 2012, no município de Arroio do Tigre/RS, realizou-se uma pesquisa de campo que objetivou caracterizar e relacionar a diversificação dos meios de vida com as condições de vida. Para tal, foram entrevistadas 38 famílias produtoras de tabaco. Em junho de 2013, realizou-se a segunda etapa desse trabalho, com entrevistas a doze famílias do município. A partir da compilação das respostas, têm-se os primeiros resultados.

Categorização dos produtores em relação ao grau de diversificação: $13 \%$ de famílias diversificadas; $26 \%$ pouco diversificadas; $61 \%$ especializadas, o que denota um considerável grau de especialização dos agricultores familiares produtores de tabaco daquele município. O mesmo pode ser verificado nas 11 entrevistas realizadas em 2013, como pode ser visto no relato da família A: "Com o tamanho da terra que temo, ou planta fumo ou não faz nada. A única coisa que dá dinheiro em três hectares é o fumo..." (Família A). Mesmo que a família tivesse gado de leite e vendesse o produto a $R \$ 0,80$ (um dos mais altos preços da região), o que "pagava as contas da família", segundo eles, vinha da venda do fumo.

De forma geral, os 38 entrevistados da primeira etapa apresentaram o Índice de Meios de Vida (IMV) de 0,626 e um Índice de Condições de Vida (ICV) de 0,615. Este resultado demonstra que as percepções dos entrevistados sobre suas condições de vida são piores em relação a seus capitais. Tal situação evidencia que as famílias pesquisadas não possuem capacitações suficientes para levarem a vida que desejam, apesar de deterem diferentes capitais/intitulamentos (SEN, 1999, 2001), como terra, moradia, equipamentos agrícolas, etc. A seguir, é possível observar os resultados dos capitais em relação à categorização das famílias. O biograma da Figura 4 demonstra o IMV segundo o grau de diversificação das famílias pesquisadas. 
Figura 3 - Biograma representativo do Índice dos Meios de Vida (IMV)

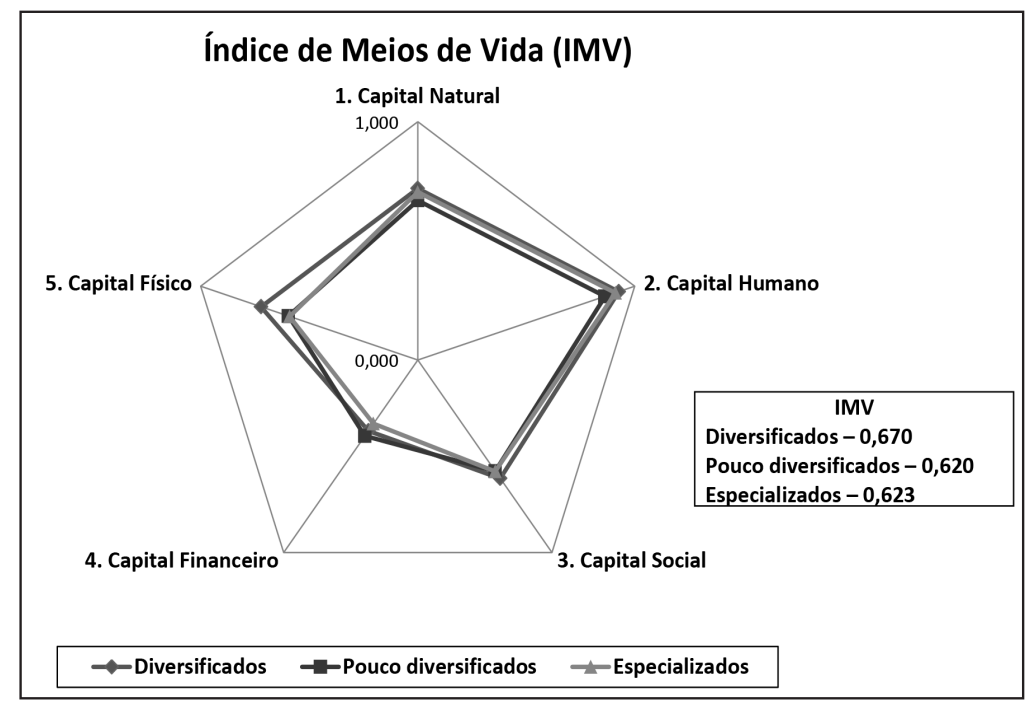

Fonte: Elaborado pelos autores.

Conforme mostra o biograma, as famílias diversificadas apresentaram melhor $\operatorname{IMV}(0,670)$, seguidas das especializadas $(0,623)$ e das pouco diversificadas $(0,620)$. Isso permite afirmar que, em relação ao conjunto dos meios para o desenvolvimento, aquelas famílias consideradas diversificadas encontram-se em uma situação mais propulsora de melhoria das condições de vida e busca de bem-estar.

Isto foi possível perceber nas entrevistas semiestruturadas, nas quais as famílias relatavam que "Além do fumo, plantamos soja, temos gado de leite e de corte e quase toda a alimentação básica é produzida na propriedade, como vegetais, hortaliças, frutas, etc., além da carne e do peixe, nos açudes" (Família B).

Outra família demonstrou, em seu depoimento, uma considerável melhoria de suas condições de vida: "Em relação ao fumo, [...] é que conseguimo construir casa, comprar trator, comprar vacas de leite sempre em função da rentabilidade com fumo, $e$ até bancar a filha fazendo faculdade em Santa Maria" (Família G).

Quanto ao Índice de Condições de Vida (ICV), a Figura 4, apresentada na página seguinte, demonstra novamente que os agricultores diversificados estão melhor posicionados, sendo seu ICV de 0,669, seguido, desta vez, dos pouco diversificados $(0,623)$ e dos especializados $(0,597)$. 


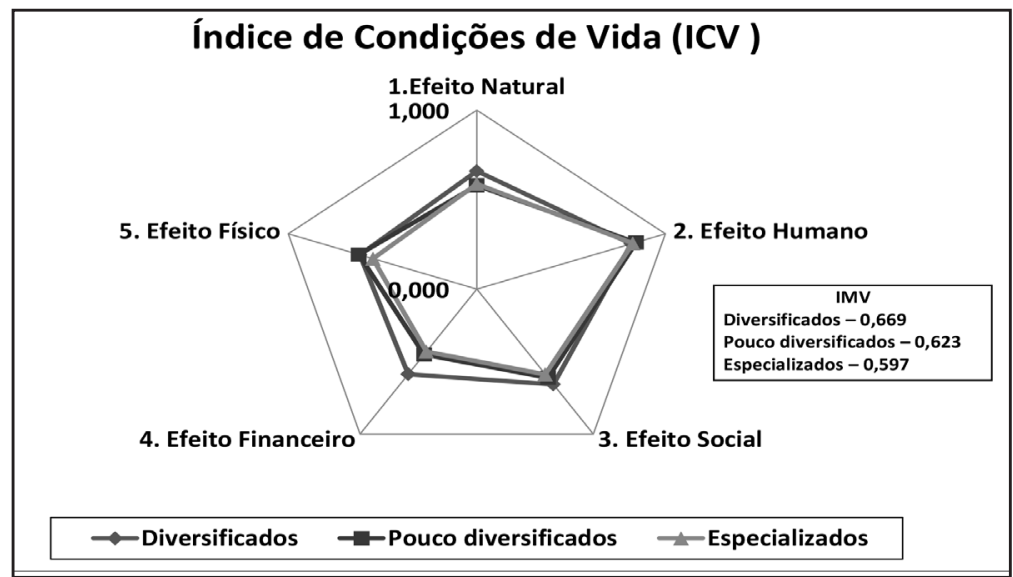

Fonte: elaborado pelos autores.

No intuito de aprofundar as análises, buscou-se um paralelo entre os capitais que as famílias possuem (IMV) e a percepção sobre os efeitos que estes geram (ICV). Conforme as Figuras 3 e 4, no caso dos agricultores diversificados, observa-se que os meios e as condições de vida alcançam praticamente o mesmo índice, 0,670 e 0,679. Os agricultores pouco diversificados também demonstram que sua percepção acerca das condições de vida $(0,623)$ se aproxima do Índice de Meios de Vida $(0,620)$. Diferentemente, os especializados são os mais insatisfeitos com suas condições: enquanto seus capitais geraram um índice de 0,623 , suas condições alcançam apenas 0,597 . Tal resultado reforça que a especialização produtiva não se traduz, necessariamente, em melhoria de bem-estar, pois os benefícios do crescimento parecem não conseguir ampliar as capacidades humanas (SEN, 2001).

Isto também pode ser comprovado em algumas entrevistas, nas quais essa insatisfação foi relatada. Segundo as famílias, E, F e I, "O Virgínia exige um trabalho especializado, este exige muito trabalho, necessita da estufa e todo o gasto que ela traz, exige uma colheita por forno, [...] (diferentemente do Burley) e que não permite escolher o 'melhor clima' e nem dia sem umidade" (Família I). Com o tipo Virgínia, as produtoras declararam que ficam "sem um dia livre" e que, de novembro até março, o trabalho é de mais de 12 horas, praticamente sem descanso, exigindo mão-de-obra de todos da família (inclusive a "ajuda dos filhos") e ainda de pessoas "de fora".

Por sua vez, ao se comparar os capitais entre si (Figura 3), é possível verificar que o capital financeiro mostra-se mais baixo nas três categorias de produtores.

Ao analisar o biograma que trata das condições de vida (Figura 4), tem-se que os diversificados apresentam melhores efeitos financeiros em relação aos especializados e pouco diversificados. Segundo Ploeg (2008), isso pode representar uma maior capacidade de agência dos agricultores diversificados, no sentido de travar sua luta pela sobrevivência e construção de autonomia através de processos de 
conversão de recursos para fins desejados, tal como sugere Sen $(2001 ; 2000)$, e na perspectiva da diversificação, como descreve Ellis (2000).

Outro ponto a ser referido é que existe uma diferença na área dos gráficos: enquanto o primeiro (IMV) (Figura 3) apresentou uma área mais irregular e menor, o segundo (Figura 4) apresentou uma área mais uniforme e maior.

Portanto, pode-se considerar que existem diferenças entre o que as famílias possuem - seus capitais - e a percepção dos efeitos desses capitais sobre suas condições de vida. As razões dessas discrepâncias podem estar associadas ao que Ploeg (2008) denomina de espaços de manobra, nos quais os agricultores mobilizam um repertório de recursos fora dos mercados, criando estratégias para manter e ampliar sua autonomia. Ou, ainda, esse resultado pode ser um indicativo daquilo que Sen (2003) chama de acomodação resignada à privação continuada e à vulnerabilidade, o que resultaria da ausência de uma forte demanda pública e de um desejo de modificar essa situação (SEN, 2003).

Mais uma vez, as concepções de Ploeg (2008) e Sen (2003) fizeram-se presentes nos relatos captados pelas entrevistas de 2013: a produtora da Família G mostrava o relevo acidentado da região, alegando que "Não há o que produzir nessas terras senão fumo e milho". Ainda, quando questionada sobre usar o curso de capacitação oferecido por uma ONG, para ter outra fonte de renda, a produtora respondeu dizendo: "Eu sei fazer outras coisas, principalmente que sejam comida, o que sempre dá dinheiro, mas não como fumo".

Já o relato da produtora da Família I mostrava que ela trabalhava na lavoura desde criança, mas, aos 9 anos, teve seu primeiro mal súbito, notando que isso se repetia todos os anos em que precisava ajudar bastante os pais e, posteriormente, o marido nas atividades da fumicultura. Sabendo de seu problema, a produtora tornou-se auxiliar de saúde e ainda busca outras formas de ganhar dinheiro e ter rendimentos extras, para conseguir outra ocupação além do fumo, principalmente trabalhando com alimentos, como doce de leite e geleias caseiras, queijo e doces, o que configura um quadro de diversificação.

Também foi possível especificar os dados apresentados por capitais e efeitos para cada grupo de agricultores. O gráfico da Figura 5, na próxima página, evidencia qual capital e qual efeito encontram-se com melhores ou piores resultados em relação ao índice. 
Figura 5: Comparação entre capitais e condições - Arroio do Tigre/RS
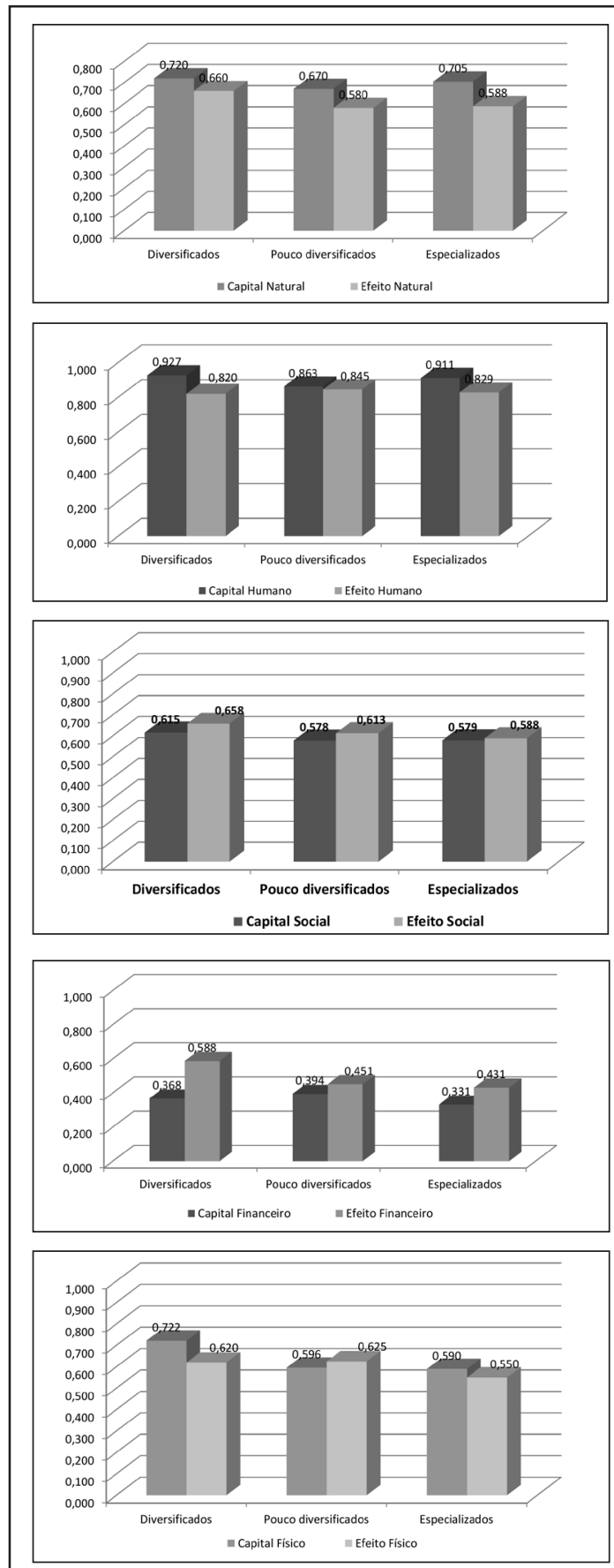

Fonte: Elaborado pelos autores. 
1 - No grupo dos diversificados, os capitais, natural $(0,720)$, humano $(0,927)$ e físico $(0,722)$, estão melhor posicionados em relação à percepção de seus efeitos. Estes efeitos apresentam um índice de 0,660; 0,820 e 0,620, respectivamente. O contrário ocorre com os capitais social $(0,615)$ e financeiro $(0,722)$, cujos efeitos representam 0,658 e 0,588 , respectivamente. Nesse grupo, a variável financeira é aquela que apresenta piores resultados, tanto no IMV quanto no ICV. Já o capital e o efeito humano são responsáveis pelos melhores índices neste grupo.

2 - Quanto ao grupo de agricultores pouco diversificados, apenas o capital natural $(0,670)$ e o humano $(0,863)$ estão melhor posicionados em relação a seus efeitos sobre as condições de vida (Figura 8). Esses efeitos apresentaram índices de 0,580 (natural) e 0,845 (humano). Os demais capitais possuem um índice inferior ao efeito: o capital social corresponde a 0,578, e seu efeito, a 0,613; o capital financeiro representa 0,394, enquanto seu efeito é de 0,451, e o capital físico, de 0,596, possui um efeito de 0,625. Tal como no grupo dos diversificados, os pouco diversificados apresentam, no aspecto financeiro, seu pior índice e, no humano, seus melhores índices.

3 - Quanto aos especializados, o capital natural $(0,705)$, humano $(0,911)$ e físico $(0,590)$ apresentaram-se melhores que seus efeitos: 0,588 (natural); 0,829 (humano) e 0,550 (físico). Já os efeitos $(0,431)$ são melhores que os capitais $(0,331)$ no quesito financeiro. O mesmo ocorre para o aspecto social: o efeito apresenta índice de 0,588, e seu capital, 0,579. Não diferente dos demais grupos, a variável financeira representa o pior índice, e a humana, o melhor.

Os gráficos demonstram que, em geral, as famílias diversificadas mostram situação menos vulnerável em relação às demais quanto aos seus capitais. Por sua vez, também fica evidente que o capital financeiro é mais vulnerável, entretanto, ao se relacionar este capital ao seu efeito, na perspectiva de relacionar meios e fins, essa conclusão pode-se mostrar precipitada.

Ainda, pelos biogramas das Figuras 3 e 4, e pelos gráficos da Figura 5, observamse os capitais e efeitos mais vulneráveis de cada grupo de produtores, evidenciando que o capital e efeito financeiro estão abaixo da média dos índices. No entanto, nos três grupos de agricultores, os efeitos financeiros são percebidos como melhores em relação ao próprio capital. Individualmente, isso pode demonstrar pouca propensão dos agricultores para diversificar suas receitas, justamente por entenderem que os efeitos são melhores que os próprios capitais, dificultando a implementação de políticas nesta dimensão, como ficou demonstrado nos relatos das famílias A e G.

Analisando as variáveis que compõem os índices, pode-se dizer que contribuíram negativamente, para o valor do índice da dimensão financeira, em ordem decrescente, a) a pequena diversificação de atividades a gerarem receitas na propriedade; b) a proporção de receitas geradas fora da propriedade; c) a diversificação dos canais de comercialização dos produtos e d) o montante de receitas destinadas ao pagamento de 
dívidas. A segunda dimensão (efeito e capital) que apresentou resultados mais baixos foi a social, e os efeitos também foram considerados melhores que os próprios capitais. Observou-se, por exemplo, que os entrevistados participam de atividades religiosas e da escola da comunidade; o acesso à informação se dá por meio de rádio, televisão, assistência técnica e extensão rural e com vizinhos, mas há pouco acesso à internet, jornais e revistas. Assim, visualiza-se que, apesar das limitações, os entrevistados mostram algum grau de satisfação ou acomodação resignada com tal situação.

Na sequência, o menor índice deu-se na dimensão natural. Nesse caso, os efeitos são compreendidos como piores em relação aos capitais. A grande maioria dos entrevistados relatou que emprega alguma prática de conservação do solo e utiliza os agrotóxicos, conforme o receituário técnico, o que contribuiu positivamente para o índice. Já, negativamente, contribuem a falta de proteção dos cursos d'água e nascentes, a baixa presença de animais silvestres nas propriedades e o uso intensivo de lenha, comprada para a secagem do tabaco Virgínia (uma vez que a exigência legal requer lenha de reflorestamento com eucalipto), dados estes que corroboram com o trabalho de Vital (2007) e Eriksen, Mackey e Ross (2012). Almeida (2005) aponta que o desmatamento para produção de lenha alcança um consumo de 1,8 milhão de toneladas de lenha/safra nos estados da região sul do Brasil.

Ademais, os resultados da pesquisa mostram os efeitos ambientais piores que os de capitais, evidenciando uma insatisfação dos agricultores com as questões que envolvem o meio ambiente nas propriedades. Conforme relato da família $A$, a tendência é que o fumo de estufa encareça, pois a lenha a ser utilizada na secagem deve ser proveniente de eucalipto de reflorestamento, preferencialmente adquirida junto à empresa, o que acentuaria um quadro de dependência de matéria-prima para a produção do tabaco (além das já existentes). Segundo as produtoras das famílias C e D: "Em função das leis ambientais e da necessidade de ser eucalipto, a empresa não deixa mais comprar lenha de qualquer outra pessoa, porque o particular não tem registro de que é árvore de reflorestamento". Ainda, as produtoras falaram que em torno de 3 a 4 hectares de suas propriedades eram de mata nativa ("mata do morro") e que "Se antes podia tirar lenha dali, agora não pode mais, pois isto dá multa com a empresa".

Quanto à dimensão física, contribuíram negativamente e em ordem decrescente: a) as máquinas e equipamentos de que as famílias dispõem; b) o montante que o tabaco representa na área da propriedade; c) a infraestrutura de acesso às propriedades; d) a infraestrutura de moradia e, e) o armazenamento das embalagens de agrotóxicos. Importante destacar a carência de máquinas e equipamentos adaptados ao porte da agricultura familiar, o que poderia acarretar uma diminuição do trabalho manual e, talvez, um aumento de tempo de trabalho dedicado a outras atividades agrícolas e não agrícolas, facilitando um processo de diversificação.

A dimensão humana foi a que apresentou índices mais elevados e efeitos melhores que os capitais, pois todos os membros das famílias foram apontados como alfabetizados; as crianças em idade escolar (quando o caso) frequentavam a escola, a maior parte dos alimentos eram produzidos nas propriedades. As variáveis que contribuíram negativamente para o índice foram as receitas gastas em remédios e a necessidade de diminuição da ingestão de bebidas alcoólicas. As questões de saúde vão ao encontro das 
constatações de Schoenhals, Follador e Silva (2009), em pesquisa realizada no estado do Paraná, os quais observaram que, mesmo os produtores de tabaco relatando que vêm sofrendo com problemas de saúde, há uma desassociação desses problemas com o cultivo do tabaco, e, consequentemente, o contato direto/indireto com agrotóxicos, demonstrando a necessidade de maiores esclarecimentos.

\section{Considerações finais}

A partir dos resultados e discussões apresentados na seção anterior, o primeiro ponto a ser observado nesta conclusão é que ainda é preciso reconhecer que, em cada dimensão, cabe pesquisar e analisar se uma percepção positiva sobre os efeitos gerados pelos capitais realmente reflete a liberdade das pessoas levarem a vida que desejam, ou se as famílias estão acomodadas e acostumadas a uma situação de privação que se tornou naturalizada. Nesse sentido, novas pesquisas qualitativas e complementares fazem-se necessárias a este estudo.

Pelo viés metodológico, pode-se dizer que o Índice dos Meios de Vida e o Índice das Condições de Vida retratam um instante, o qual pode ser comparado com um instante posterior, ou com um recorte espacial distinto, podendo-se, assim, observar a dinâmica dos meios e condições de vida. A elaboração do IMV e do ICV, aplicada às áreas de agricultura familiar produtora de tabaco, representou um esforço no sentido de elaborar instrumentos de pesquisa que incorporem uma concepção mais holística e multidimensional do conceito de desenvolvimento, conforme as proposições de autores como Amartya Sen e Frank Ellis.

Outro avanço da abordagem utilizada neste trabalho é a atenção prestada à percepção dos indivíduos entrevistados. Grande parte dos índices que propõem apreender o desenvolvimento, mesmo que de forma multidimensional, são baseados em dados secundários. Dessa forma, dificilmente seria possível aproximar-se do que Sen denomina liberdade para levar a vida que se almeja, tal como se pode perceber por meio do ICV agregado ao IMV.

Ademais, o esforço em distinguir meios e fins também possibilitou uma visão mais integral do desenvolvimento, uma vez que os instrumentos apontaram discrepâncias entre o que as famílias possuem e como elas percebem esses recursos de forma a torná-los um meio para o desenvolvimento, a partir da diversificação. Como reforça Ellis (2000), na medida em que um ativo puder ser construído, adquirido, modificado ou convertido em outro, maior será a possibilidade de sucesso das respostas de enfrentamento ou adaptação dos meios de vida, melhorando, consequentemente, as condições de vida dos agricultores e suas famílias.

É importante também relatar os desafios encontrados neste trabalho, como, por exemplo, entender as razões que determinam resultados distintos entre capitais e seus respectivos efeitos, avaliar em que medida as variáveis utilizadas são as que melhor expressam os meios e as condições de vida, bem como se os critérios de classificação quanto ao grau de diversificação são suficientes e adequados. Outro ponto a ser relatado é que houve uma tendência a alternativas medianas nas respostas, quando se captou a percepção da família, um obstáculo bastante comum em trabalhos que pretendem 
valer-se da subjetividade. Mas, ao que se observou neste trabalho, relacionar dados objetivos - o que foi possível por meio do instrumento que dá origem ao IMV - com a percepção - captada pelo ICV - mostrou-se como uma forma de minimizar, em alguma medida, esta questão.

De toda forma, entende-se este trabalho como uma importante contribuição às discussões sobre desenvolvimento humano, qualidade de vida e diversificação, uma vez que aponta elementos pertinentes à análise da diversidade de realidades que existem no âmbito da agricultura familiar, em especial, a produtora de tabaco. Compreender as estratégias desenvolvidas pelos indivíduos e/ou famílias (ELLIS, 2000), com base em suas capacidades, conhecimentos e trajetórias locais, torna-se essencial frente ao reconhecimento de que o futuro do mundo rural será determinado pelo modo como os agricultores (e demais atores) serão capazes de gerir e explorar a diversidade expressa por seus ativos, em contrapartida às ideias de especialização produtiva decorrentes da Revolução Verde e de um processo de "modernização" do meio rural.

Nesse sentido, é preciso pensar que, para além da ideia de produção, produtividade e eficiência agrícola, os meios de vida dos agricultores sofrem influência das relações sociais, das instituições e de organizações atuantes em diferentes escalas e ao longo do tempo; das condições ambientais, e não apenas de aspectos econômicos, conforme as análises aqui apresentadas. Assim, o desencadeamento de processos de desenvolvimento, no meio rural, deve ir além de transferência de renda ao agricultor e da eficiência na produtividade. Portanto, a abordagem das capacitações, aliada à abordagem dos meios de vida, pode acrescentar, significativamente, novos elementos às discussões sobre desenvolvimento humano e qualidade de vida.

\section{Referências}

ALMEIDA, Guilherme Eidt Gonçalves de. Fumo. Servidão moderna e violações de direitos humanos. Curitiba: Terra de Direitos, 2005. Disponível em:

$<$ http://actbr.org.br/uploads/conteudo/594_Fumo_serv_moderna_livro.pdf >. Acesso em: 20 jan. 2014.

BEBBINGTON, Anthony. Capitals and capabilities. London: Internacional Institute for Environment and Development, 1999.

ELLIS, Frank. Rural livelihoods and diversity in developing countries. Oxford: Oxford University, 2000.

ERIKSEN, Michael; MACKAY, Judith; ROSS, Hana. The Tobacco Atlas. Fourth Ed. Atlanta, GA: American Cancer Society; New York, NY: World Lung Foundation; 2012. Disponível em: <http://www.tobaccoatlas.org/>. Acesso em: 20 jan. 2014.

HERCULANO, Selene. A Qualidade de Vida e seus Indicadores. In: HERCULANO, S. et al. (Org.). Qualidade de Vida e Riscos Ambientais. Niterói: Eduff, 2000.

KAGEYAMA, Angela A. Desenvolvimento rural: conceitos e aplicação ao caso brasileiro. Porto Alegre: UFRGS, 2008. 
NIEDERLE, Paulo; GRISA, Cátia. Diversificação dos meios de vida e acesso a atores e ativos: uma abordagem sobre a dinâmica de desenvolvimento local da agricultura familiar. 2008. Cuadernos de Desenvolvimento Rural, Bogotá, Colombia, ano 5, v. 61, p. 41-69, jul./dez. 2008.

PERONDI, Miguel et al. A estratégia de diversificação dos meios de vida: o estudo da trajetória de uma família rural no Sudoeste do Paraná. 2009. Anais. $47^{\circ}$ Congresso da Sociedade Brasileira de Economia, Administração e Sociologia Rural, Porto Alegre, 26 a 30 de julho de 2009.

PLOEG, J. D. van der. Camponeses e impérios alimentares: lutas por autonomia e sustentabilidad na era da globalização. Porto Alegre: UGRGS, 2008. (Coleção Estudo Rurais).

SCHNEIDER, Sergio. A abordagem territorial do desenvolvimento rural e suas articulações externas. Sociologias, Porto Alegre, ano 6, n. 11. p. 88-125, jan./jun. 2004.

. Diversificação como estratégia de desenvolvimento rural: referências teóricas para construção de alternativas economicamente sustentáveis de diversificação da produção e renda em áreas de cultivo do tabaco no Brasil - subsídios à implementação dos Artigos 17 e 18 da Convenção-Quadro para Controle do Tabaco. Porto Alegre, 2010a. (Relatório).

. Subsídios técnicos ao Grupo de Trabalho para a Implementação dos Artigos 17 e 18 da Convenção Quadro para o Controle do Tabaco. Porto Alegre, 2010b. (Relatório).

SCHNEIDER, Sergio; FREITAS, Tanise D. Qualidade de Vida, Diversificação e Desenvolvimento: referências práticas para análise do bem estar no meio rural. Revista Olhares Sociais, n. 2, p. 121-142, jan./jun. 2013.

SCOONES, Ian. Livelihoods perspectives and rural development. Journal of Peasant Studies, v. 36, n. 1, January, 2009.

SEN, Amartya K. Capacidad y Bienestar. In: NUSSBAUM, Martha C.; SEN, Amartya. La Calidad de Vida. México: Fondo de Cultura Económica, 1996.

. Desenvolvimento como liberdade. São Paulo: Companhia das Letras, 2000. . Desigualdade reexaminada. Rio de Janeiro: Record, 2001. . O desenvolvimento como expansão de capacidades. Revista Lua Nova, São Paulo, p. 28-29, abr. 2003.

SCHOENHALS, Marlise; FOLLADOR, Franciele Aní Caovilla; SILVA, Caciana da. Análise dos impactos da fumicultura sobre o meio ambiente, à saúde dos fumicultores e iniciativas de gestão ambiental na indústria do tabaco. Revista de Engenharia Ambiental, Espírito Santo do Pinhal, v. 6, n. 2, p. 16-37, maio/ago. 2009.

VEIGA, José Eli da. Meio Ambiente e Desenvolvimento. São Paulo: Senac, 2006. 
VITAL, Marcos H. E. 2007. Impacto ambiental de florestas de eucalipto. Revista do BNDES, Rio de Janeiro, v. 14, n. 28, p. 235-276, dez. 2007.

WAQUIL, Paulo D. et al. Proposição do Índice de Condições de Vida. Porto Alegre: PGDR/UFRGS, SDT/MDA, 2007. (Relatório de pesquisa). 